\title{
Chloroplast genome variation and phylogenetic relationships of Atractylodes species
}

\author{
Yiheng Wang ${ }^{1 \dagger}$, Sheng Wang ${ }^{1 \dagger}$, Yanlei Liu², Qingjun Yuan1, Jiahui Sun ${ }^{1 *}$ and Lanping Guo ${ }^{1 *}$
}

\begin{abstract}
Background: Atractylodes DC is the basic original plant of the widely used herbal medicines "Baizhu" and "Cangzhu" and an endemic genus in East Asia. Species within the genus have minor morphological differences, and the universal DNA barcodes cannot clearly distinguish the systemic relationship or identify the species of the genus. In order to solve these question, we sequenced the chloroplast genomes of all species of Atractylodes using highthroughput sequencing.

Results: The results indicate that the chloroplast genome of Atractylodes has a typical quadripartite structure and ranges from 152,294 bp (A. carlinoides) to 153,261 bp (A. macrocephala) in size. The genome of all species contains 113 genes, including 79 protein-coding genes, 30 transfer RNA genes and four ribosomal RNA genes. Four hotspots, rpl22-rps19-rpl2, psbM-trnD, $\operatorname{trnR} R$-trn $T^{(\mathrm{GGU})}$, and $\operatorname{trn} T^{(\mathrm{UGU})}$-trnL, and a total of 42-47 simple sequence repeats (SSR) were identified as the most promising potentially variable makers for species delimitation and population genetic studies. Phylogenetic analyses of the whole chloroplast genomes indicate that Atractylodes is a clade within the tribe Cynareae; Atractylodes species form a monophyly that clearly reflects the relationship within the genus.
\end{abstract}

Conclusions: Our study included investigations of the sequences and structural genomic variations, phylogenetics and mutation dynamics of Atractylodes chloroplast genomes and will facilitate future studies in population genetics, taxonomy and species identification.

Keywords: Traditional herbal medicine, Chloroplast markers, Simple sequence repeat, Indel, Interspecific relationships

\section{Background}

Chloroplasts are multifunctional organelles with independent genetic material, which are commonly found in terrestrial plants, algae and a few protozoa. There are multiple configurations of the chloroplast genome in the cell; the most common structure is double-stranded circular configuration including a small single copy region (SSC) and a large single copy region (LSC). These two

\footnotetext{
*Correspondence: sunjh_2010@sina.com; glp01@126.com

${ }^{+}$Yiheng Wang and Sheng Wang contributed equally to this work.

${ }^{1}$ National Resource Center for Chinese Materia Medica, China Academy of Chinese Medical Sciences, Beijing 100700, China

Full list of author information is available at the end of the article
}

regions are separated by a pair of inverted repeat regions (IRa, IRb) to form a typical quadripartite structure. The genome size ranges from 120 to $160 \mathrm{~kb}$ [1]. Compared with the mitochondrial or nuclear genome, the plant chloroplast genome has a higher conservation in terms of structure, gene number and gene composition. The evolution rate is relatively moderate and is between the nuclear and mitochondrial genome [2]. Due to the lack of recombination, small genome size and high copy number per cell [3,4], complete chloroplast genome sequences have been extensively used in phylogenetics analysis and species identification $[5,6]$. The results showed that the chloroplast genome contains additional

(c) The Author(s). 2021 Open Access This article is licensed under a Creative Commons Attribution 4.0 International License, which permits use, sharing, adaptation, distribution and reproduction in any medium or format, as long as you give appropriate credit to the original author(s) and the source, provide a link to the Creative Commons licence, and indicate if changes were made. The images or other third party material in this article are included in the article's Creative Commons licence, unless indicated otherwise in a credit line to the material. If material is not included in the article's Creative Commons licence and your intended use is not permitted by statutory regulation or exceeds the permitted use, you will need to obtain permission directly from the copyright holder. To view a copy of this licence, visit http://creativecommons.org/licenses/by/4.0/ The Creative Commons Public Domain Dedication waiver (http://creativecommons.org/publicdomain/zero/1.0/) applies to the data made available in this article, unless otherwise stated in a credit line to the data. 
information to improve phylogenetic analysis [7-11]. Comparative chloroplast genome sequences provide an opportunity to discover the sequence variation and identify mutation hotspot regions, while also detecting the gene loss and duplication events. Mutation hotspot regions and single sequence repeats (SSRs) obtained from the chloroplast genome sequences can be effective molecular markers for species identification and population genetics [12].

Atractylodes is a small East Asian endemic genus of the Asteraceae family with 6 species and is distributed in China, Japan, and the Korean Peninsula. Traditional Chinese herbal medicines "Baizhu" and "Cangzhu" originate from Atractylodes [13]. It is the traditional medicine for treatment of gastroduodenal diseases. All species of the genus have been used as an herbal medicine except $A$. carlinoides. The "Pharmacopoeia of the People's Republic of China" states that "Cangzhu" is the dried rhizome of $A$. lancea and "Baizhu" is the dry rhizome of $A$. macrocephala. However, traditional medicine in Japan considers $A$. lancea, $A$. coreana and $A$. chinensis "Cangzhu" and A. japonica and A. macrocephala "Baizhu" [14]. Similar medicinal effects and mixed use reflect the complexity of the systematic relationship of the original plant. Indeed, the genus Atractylodes was identified as early as 1838 ; however, the relationship between and within the genus has never ceased to be controversial.

The morphological variation in this genus is relatively large and the relationships are difficult to determine by traditional identification. A. carlinoides has pinnatifid, rosulate basal leaves, whereas A. macrocephala has branched stem from base, which easy to distinguish from other species (Fig. 1). But the other four species are difficult to distinguish from each other morphologically, especially when the plants are young and have unbranched stems and undivided leaves.

Several studies have used several chloroplast markers, such as atpB-rbcL trnK, trnL-F, and/or nuclear ITS, to determine the relationship of the genus [15-17]. However, the phylogenetic relationships within Atractylodes have been poorly defined because of limited number of DNA sequences and low number of the variation markers. In this study, we sequenced the chloroplast genome of all six Atractylodes species. The objectives of this study were (1) to compare the chloroplast genome of Atractylodes to understand the evolution of the genome structure, (2) to determine the highly variable regions for species identification, and (3) to clarify the phylogenetic relationship of Atractylodes.
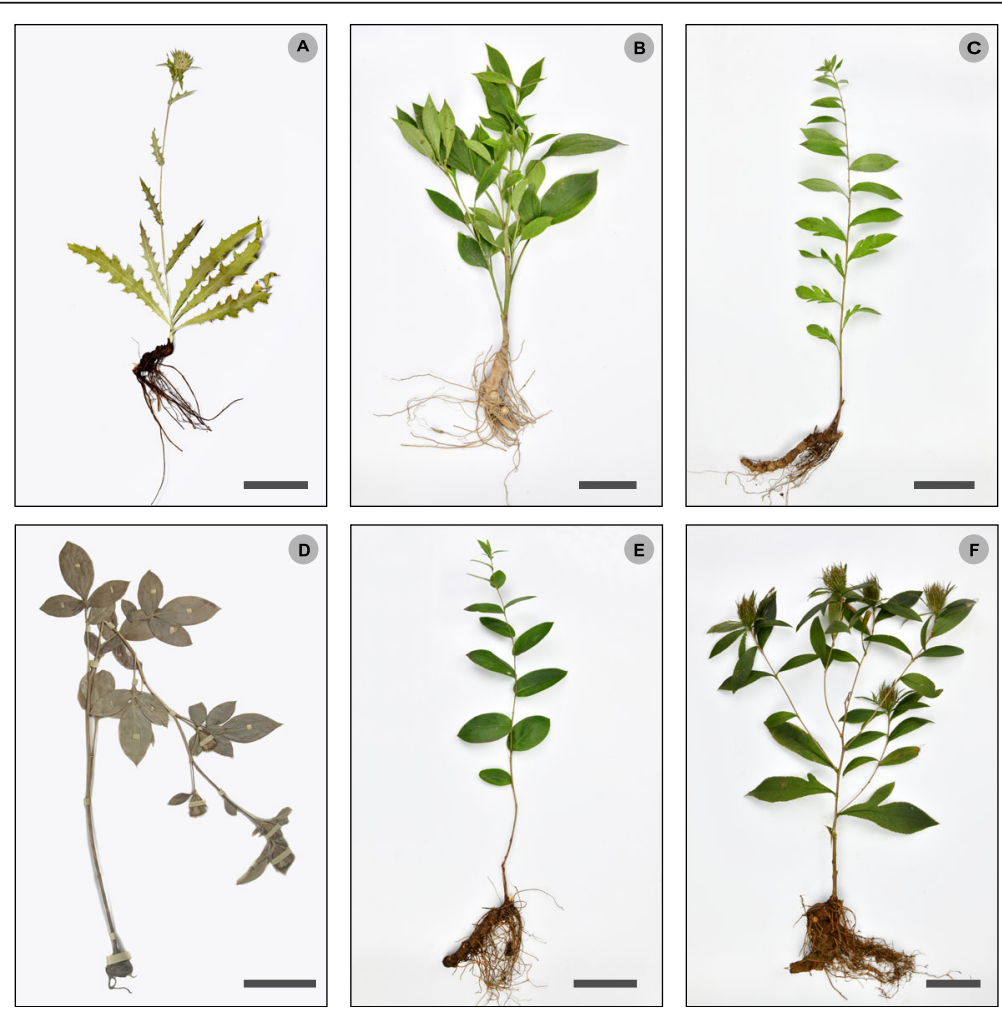

Fig. 1 Comparison of vegetal morphologies among Atractylodes species. Scale bars are $5 \mathrm{~cm}$. A A. carlinoides, B A. macrocephala, C A. lancea, D A. japonica, E A. coreana, $\mathbf{F}$ A. chinensis 


\section{Results}

Chloroplast genome sequencing and features of Atractylodes species

Six Atractylodes species were used to obtain 10,016,902 - 44,594,826 raw reads with the average coverage of 67X - 1431X (Table 1). Six complete chloroplast genome sequences were deposited in GenBank with accession numbers MT834519 to MT834524. The total chloroplast genome size ranged from 152,294 bp (A. carlinoides) to 153,261 bp (A. macrocephala). The Atractylodes chloroplast genome has a typical quadripartite structure and includes a pair of IR regions (25,132 bp - 25,153 bp), LSC regions $(83,359 \mathrm{bp}-84,281 \mathrm{bp})$ and SSC regions $(18,634 \mathrm{bp}-18,707 \mathrm{bp})$. The average GC content is $37.7 \%$ in the total chloroplast genome, $43.2 \%$ in IR, $35.8-35.9 \%$ in LSC, and 31.4-31.6\% in SSC; there are almost no differences between the six Atractylodes chloroplast genomes.

The chloroplast genome of Atractylodes has 113 genes, including 79 protein-coding genes, 30 transfer RNA genes and four ribosomal RNA genes (Fig. 2, Table 2). Six protein-coding genes $(n d h B, r p l 23, r p s 7, r p s 12, y c f 2$, and rpl2), seven tRNA genes (trnI-CAU, trnL-CAA, $\operatorname{trn} V-G A C$, trnI-GAU, trnA-UGC, trnR-ACG and trnN$G U U)$ and all four rRNA genes are duplicated in the IR regions. Fourteen genes (atpF, rpoC1, ndhB, petB, rpl2, $n d h A$, rps12, rps16, trnA-UGC, trnI-GAU, trnK-UUU,

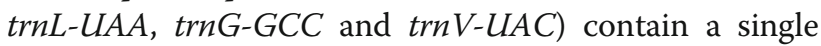
intron and two genes (clpP and $y c f 3)$ have two introns. The rps12 gene is a trans-spliced gene with $5^{\prime}$-end located in the LSC region and the $3^{\prime}$ end located in the IR region. The gene trnK-UUU has the largest intron, which contains the matK gene.

\section{Indels}

There are 114 indels in six Atractylodes chloroplast genomes, including 30 SSR-related indels (26.3\%) and 84 non-SSR-related indels (73.7\%); 74.6\% indels are present in 42 intergenic space regions, $7.0 \%$ indels are located in exons, and $18.4 \%$ are present in the introns (Fig. 3a, Table S1). The trnT-trnL gene contains six indels; the trnE-rpoB, ndhC-trn $M$ and $y c f 1$ genes contain 5 indels followed by the rpl32-ndhF and trnL-rpl32 genes with 4 indels.

All SSR-related indels are single nucleotide size except an indel located in the ndhB-trnL region, which is $6 \mathrm{bp}$ in size. The majority of the SSR-related indels are related to the A/T type SSRs (28 times). All SSR-related indels are located in the non-coding regions.

The size of the non-SSR-related indels ranges from 1 to $971 \mathrm{bp}$, with one bp indels being the most common (Fig. 3b). The largest indel $(971 \mathrm{bp})$ in the spacer of $n d h C$-trnM is a deletion in A. carlinoides. The second largest indel is in the exon of $y c f 1$ with $30 \mathrm{bp}$ size and is a deletion in $A$. lancea and an insertion in $A$. coreana. The majority of the NR-indels are located in the noncoding regions $(91.67 \%)$, including $73.81 \%$ in the intergenic spaces and $17.86 \%$ in introns.

\section{SSRs}

A total of 265 SSRs were detected in the chloroplast genomes of six Atractylodes species by the GMATA analysis.

Table 1 The basic chloroplast genome information of six Atractylodes species

\begin{tabular}{|c|c|c|c|c|c|c|}
\hline Characteristics & A. chinensis & A. coreana & A. lancea & A. macrocephala & A. japonica & A. carlinoides \\
\hline Raw data no. & $10,016,902$ & $38,042,502$ & $42,933,804$ & $44,594,826$ & $12,772,648$ & $15,350,264$ \\
\hline Mapped read no. & 373,164 & 262,561 & $1,142,990$ & $1,462,514$ & 68,040 & 116,137 \\
\hline Percent of chloroplast genome reads(\%) & 3.73 & 0.69 & 2.66 & 3.28 & 0.53 & 0.76 \\
\hline Chloroplast genome coverage $(X)$ & 365 & 257 & 1119 & 1431 & 67 & 114 \\
\hline Total size(bp) & 153,177 & 153,201 & 153,181 & 153,261 & 153,198 & 152,294 \\
\hline LSC length(bp) & 84,241 & 84,198 & 84,255 & 84,281 & 84,254 & 83,359 \\
\hline IR length(bp) & 25,147 & 25,148 & 25,146 & 25,153 & 25,140 & 25,132 \\
\hline sSC length(bp) & 18,642 & 18,707 & 18,634 & 18,674 & 18,664 & 18,671 \\
\hline Total genes & 113 & 113 & 113 & 113 & 113 & 113 \\
\hline Protein coding genes & 79 & 79 & 79 & 79 & 79 & 79 \\
\hline tRNA genes & 30 & 30 & 30 & 30 & 30 & 30 \\
\hline rRNA genes & 4 & 4 & 4 & 4 & 4 & 4 \\
\hline Overall GC content(\%) & $37.70 \%$ & $37.70 \%$ & $37.70 \%$ & $37.70 \%$ & $37.70 \%$ & $37.70 \%$ \\
\hline GC content in LSC(\%) & $35.80 \%$ & $35.80 \%$ & $35.80 \%$ & $35.80 \%$ & $35.80 \%$ & $35.90 \%$ \\
\hline GC content in IR(\%) & $43.20 \%$ & $43.20 \%$ & $43.20 \%$ & $43.20 \%$ & $43.20 \%$ & $43.20 \%$ \\
\hline GC content in SSC(\%) & $31.50 \%$ & $31.50 \%$ & $31.50 \%$ & $31.60 \%$ & $31.60 \%$ & $31.36 \%$ \\
\hline Accession number & MT834519 & MT834521 & MT834522 & MT834520 & MT834523 & MT834524 \\
\hline
\end{tabular}




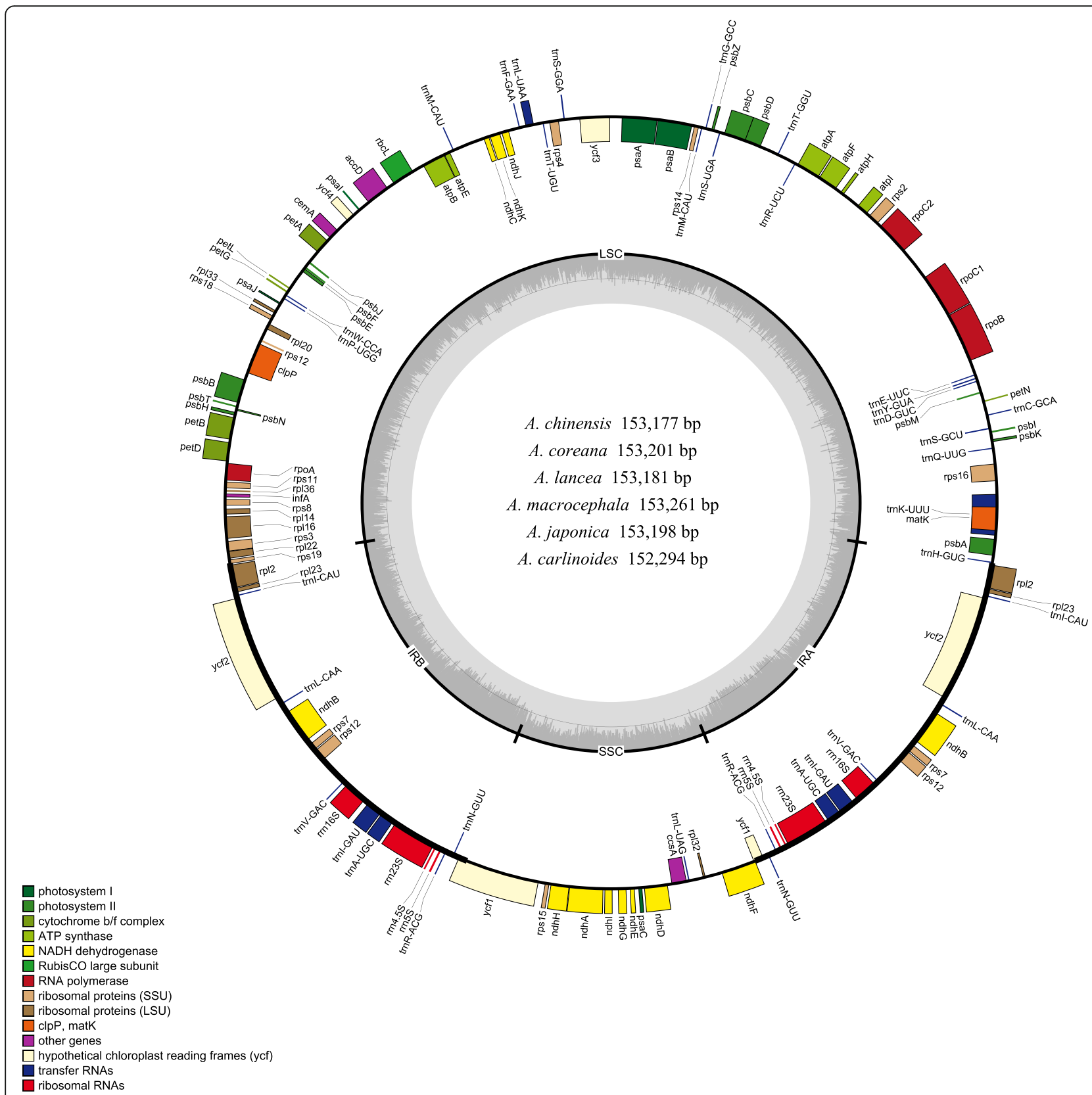

Fig. 2 Gene maps of the chloroplast genomes of Atractylodes. Genes on the inside of the large circle are transcribed clockwise and those on the outside are transcribed counter clockwise. The genes are color-coded based on their functions. The dashed area represents the GC composition of the chloroplast genome

The number of SSRs ranges from 42 (A. carlinoides) to 47 (A. lancea). SSR events are distributed randomly in the chloroplast genome. There are 210 SSRs in LSC, 28 in SSC, and 27 in the IR region (149 in spacers, 33 in introns and 83 in exons). With regard to individual genomes, the majority of SSRs were detected in LSC (ranging from $75.0 \%$ in A. lancea to $83.7 \%$ in A. japonica) and in spacers (ranging from $54.5 \%$ in A. lancea to $59.1 \%$ in A. macrocephala) (Fig. 3a). The most common SSRs are mononucleotides, which account for $71 \%$, followed by tetranucleotides accounting for $14 \%$, and dinucleotide SSRs accounting for 7\% (Fig. 4b). Nearly all mononucleotide SSRs (99\%) are composed of A and $\mathrm{T}$ in all six species. The dinucleotide repeats of TA and the tetranucleotide repeats of TTTC are the second most common SSRs (Fig. 4c).

\section{Sequence divergence and hotspots}

A comparative analysis based on mVISTA was performed in the six chloroplast genomes of Atractylodes to determine the level of divergence (Fig. 5). The results 
Table 2 The basic chloroplast genome information of six Atractylodes species

\begin{tabular}{|c|c|c|}
\hline Category for genes & Group of genes & Name of genes \\
\hline \multirow{8}{*}{$\begin{array}{l}\text { Photosynthesis related } \\
\text { genes }\end{array}$} & Rubisco & $r b c L$ \\
\hline & Photosysteml & psaA,psaB,psaC,psal,psaJ \\
\hline & $\begin{array}{l}\text { Assembly/stability of } \\
\text { photosysteml }\end{array}$ & ${ }^{*} y \subset f 3, y c f 4$ \\
\hline & Photosystemll & psbA,psbB,psbC,psbD,psbE,psbF,psbH,psbl,psbJ,psbK,psbL,psbM,psbN,psbT,psbZ \\
\hline & ATP synthase & $\operatorname{atp} A, \operatorname{atp} B, \operatorname{atp} E,{ }^{*} a t p F, \operatorname{atpH}$, atpl \\
\hline & $\begin{array}{l}\text { cytochrome b/f } \\
\text { compelx }\end{array}$ & pet $A,{ }^{*}$ pet $B,{ }^{*}$ pet $D$, pet $G$, pet $L$, pet $N$ \\
\hline & $\begin{array}{l}\text { cytochrome c } \\
\text { synthesis }\end{array}$ & $\operatorname{cCs} A$ \\
\hline & $\begin{array}{l}\mathrm{NADPH} \\
\text { dehydrogenase }\end{array}$ & ${ }^{*} n d h A,{ }^{*} n d h B, n d h C, n d h D, n d h E, n d h F, n d h G, n d h H, n d h l, n d h J, n d h K$ \\
\hline \multirow{3}{*}{$\begin{array}{l}\text { Transcription and } \\
\text { translation related genes }\end{array}$} & transcription & $r p o A, r p o B,{ }^{*} r p o C 1, r p o C 2$ \\
\hline & ribosomal proteins & $\begin{array}{l}\text { rps2, rps3, rps4, rps7, rps8, rps11, }{ }^{*} r p s 12, r p s 14, r p s 15,{ }^{*} r p s 16, r p s 18, r p s 19,{ }^{*} r p 12, r p / 14,{ }^{*} r p / 16, r p 120, \\
r p / 22, r p / 23, r p / 32, r p 133, r p / 36\end{array}$ \\
\hline & $\begin{array}{l}\text { translation initiation } \\
\text { factor }\end{array}$ & $\operatorname{infA}$ \\
\hline \multirow[t]{2}{*}{ RNA genes } & ribosomal RNA & $r r n 5, r r n 4.5, r r n 16, r r n 23$ \\
\hline & transfer RNA & 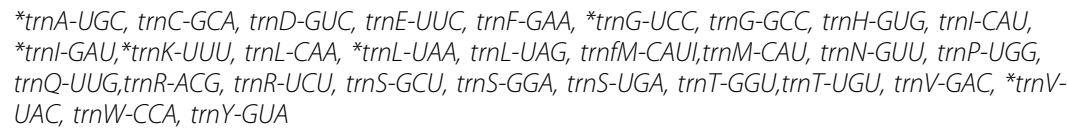 \\
\hline \multirow[t]{4}{*}{ Other genes } & RNA processing & matk \\
\hline & carbon metabolism & cemA \\
\hline & fatty acid synthesis & $a c c D$ \\
\hline & proteolysis & ${ }^{*} \mathrm{clp} P$ \\
\hline $\begin{array}{l}\text { Genes of unknown } \\
\text { function }\end{array}$ & $\begin{array}{l}\text { conserved reading } \\
\text { frames }\end{array}$ & $y c f 1, y c f 2$ \\
\hline
\end{tabular}

Intron-containing genes are marked by asterisks (*)

indicate high sequences similarities across the chloroplast genome suggesting that the chloroplast genomes are highly conserved. The IR regions and the coding regions are more conserved than the single copy regions and the noncoding regions. The coding regions of the clpP, $y c f 1$ and rps19 genes are more variable than the coding regions of other genes.
Additionally, we compared single nucleotide substitutions and nucleotide diversity in the total, LSC, SSC and IR regions of the chloroplast genomes (Table 3). Six Atractylodes chloroplast genomes were aligned with a matrix of $153,560 \mathrm{bp}$ with 445 variable sites $(0.29 \%)$ and 31 parsimony-informative sites $(0.02 \%)$. The average nucleotide diversity value was 0.001 . The
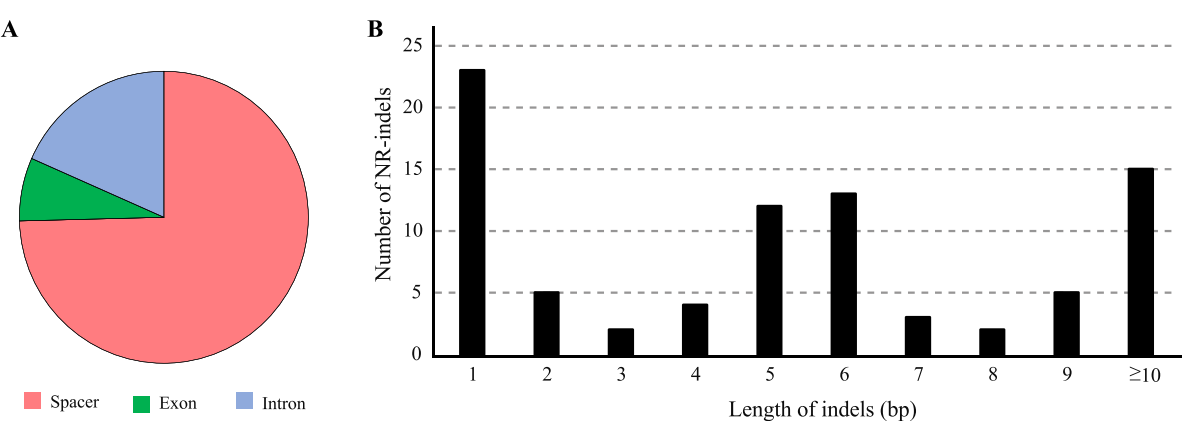

Fig. 3 Analyses of indels in the Atractylodes chloroplast genomes. (A) Frequency of indel types and locations. (B) Number and size of non-SSRrelated indels in the six Atractylodes chloroplast genomes 


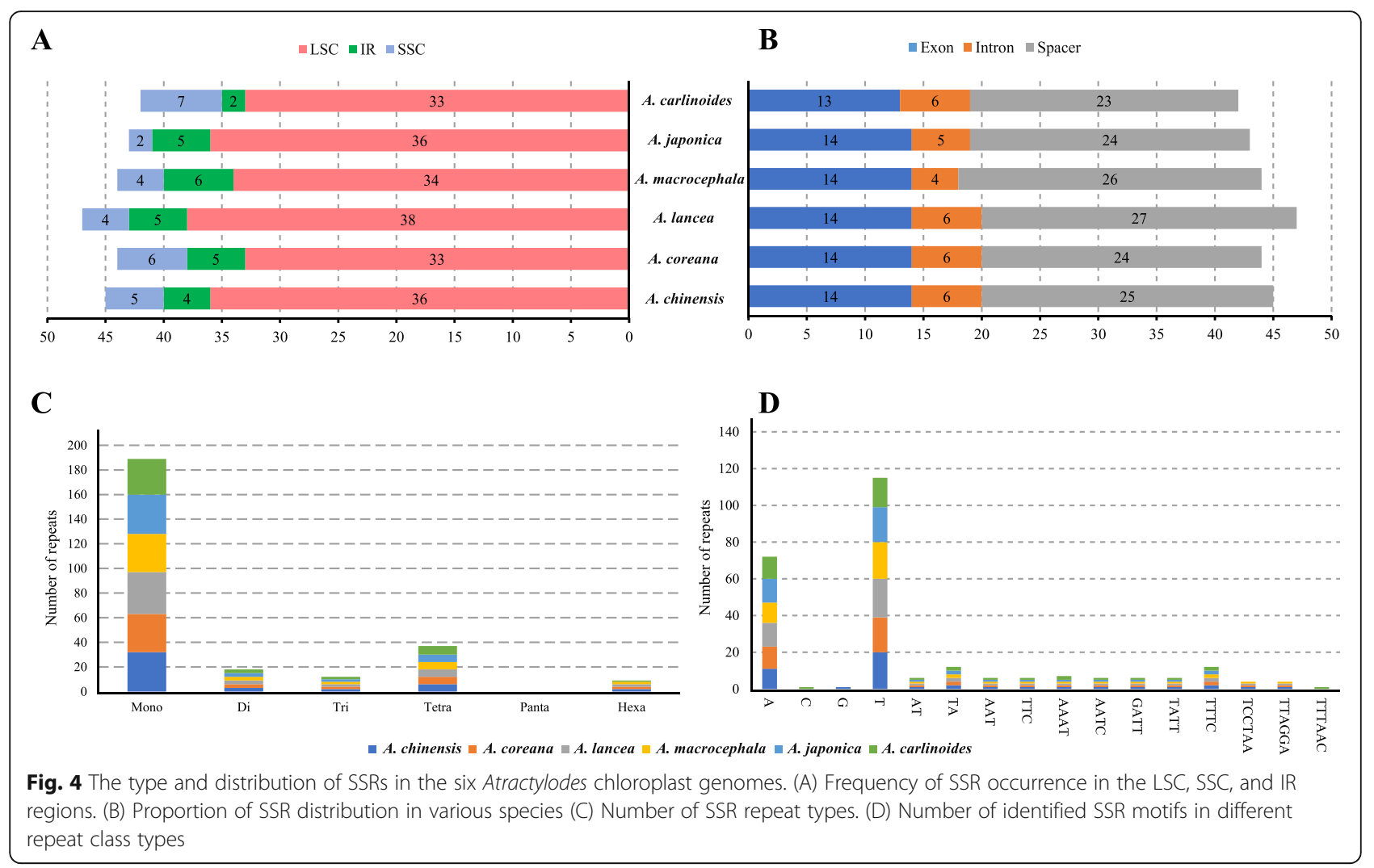

IR regions have the lowest nucleotide diversity $(0.0003)$ and the SSC regions have the highest diversity (0.0018).

The nucleotide diversity was measured by DNAsp to identify the mutation hotspot regions in the whole Atractylodes chloroplast genomes (Fig. 6). Nucleotide diversity values within $600 \mathrm{bp}$ vary from 0 to 0.00656 in group A and from 0 to 0.00633 in group $\mathrm{B}$. The region rpl22-rps19-rpl2 has the highest $\mathrm{Pi}$ values $(\mathrm{Pi}=0.00656)$ followed by the other three spacer regions $(\mathrm{Pi}>0.005)$ including $p s b M-\operatorname{trn} D$, trnR-trnT $T^{(\mathrm{GGU})}$, and $\operatorname{trn} T^{(U G U)}$ $\operatorname{trn} L$ in the group A dataset; all these features are located in the LSC region. On the other hand, group B shares lower diversity; however, the region rpl22-rps19-rpl2 still has the highest diversity. The variability of four identified mutation hotspot regions was tested together with three universal chloroplast DNA barcodes (matK, rbcL and $\operatorname{trnH}-p s b A$ ). The universal DNA barcodes had lower variability than that of the newly identified markers.

\section{Phylogenetic analysis}

Using the whole plastome sequences, we preformed phylogenetic analysis of the 37 tribe Cynareae species. The topologies of the ML and BI trees are essentially consistent (Fig. 7). Atractylodes is a sister of other Cynareae species and Atractylodes species form a monophyletic group with $100 \%$ support. Within Atractylodes,
A. carlinoides is located at the base. A. japonica and $A$. lancea cluster into a subclade and form a sister relationship with the subclade of $A$. chinensis and A. coreana. The phylogenetic relationship carried out by indels is consistent with the results obtained by using the whole plastome sequences (Fig. S1).

\section{Discussion}

The chloroplast genome of Atractylodes

In this study, the chloroplast genomes of six Atractylodes species were sequenced by the NGS methods. The chloroplast genome size ranges from 152,294 bp (A. carlinoides) to $153,261 \mathrm{bp}$ (A. macrocephala). All species have 113 genes, including 79 protein-coding genes, 30 transfer RNA genes and four ribosomal RNA genes, in the chloroplast genome. In this study, we did not annotate the $y c f 15$ and $y c f 68$ genes because we identified them as pseudogenes containing several internal stop codons [18]. In certain cases, $y c f 2, r p l 23$ and $a c c D$ are absent from the chloroplast genomes [19-21]; however, but these genes are indeed present in Atractylodes. The chloroplast genome is conserved similar to the majority of plants; no rearrangement events were detected in all species. The mVISTA results and nucleotide diversity tests indicate high similarities between the chloroplast genomes implying that the divergence of the Atractylodes 


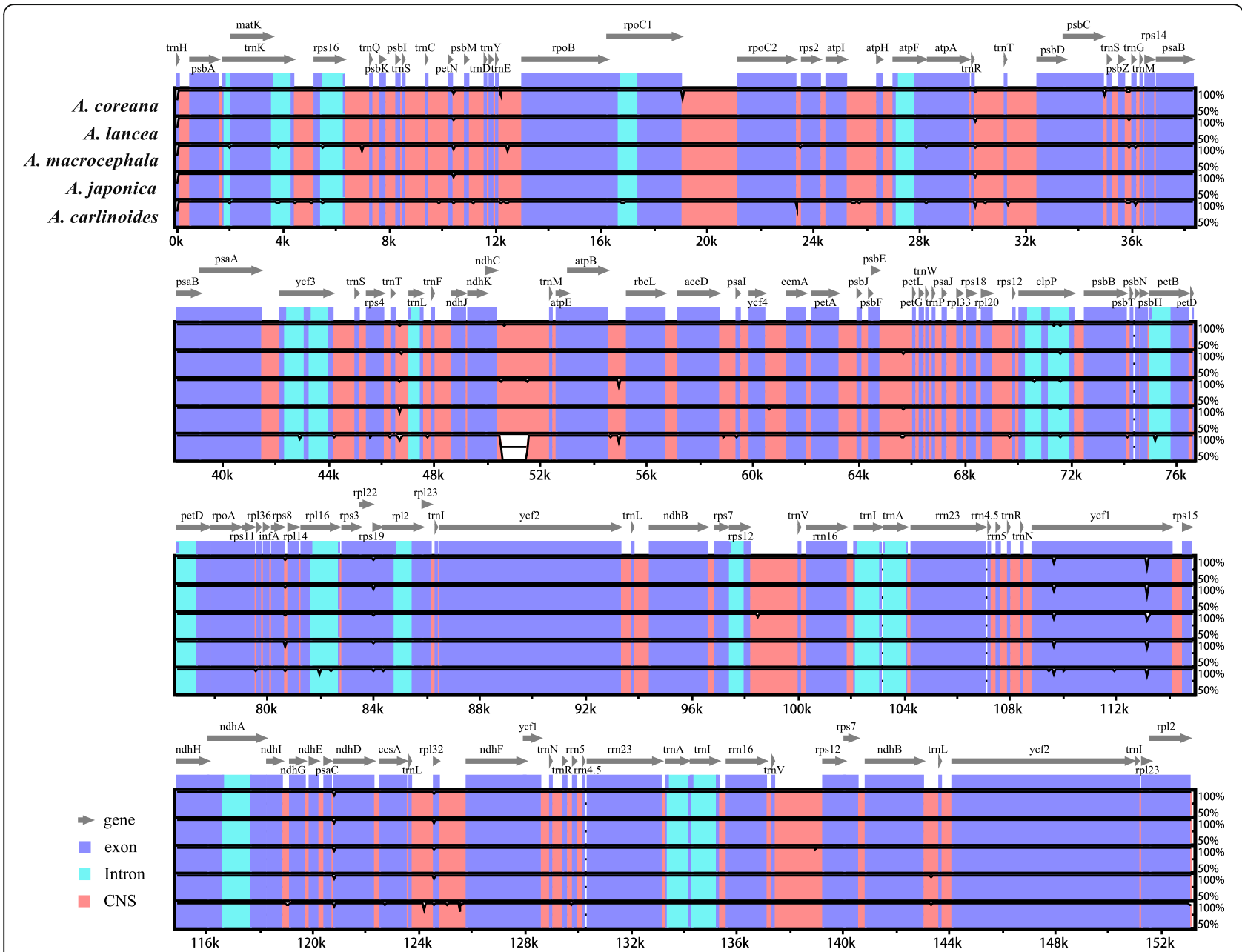

Fig. 5 Visualization of genome alignment of the chloroplast genomes of six Atractylodes species using A. chinensis as a reference by mVISTA. The $x$-axis represents the coordinate in the chloroplast genome. The sequence similarity of the aligned regions is shown as horizontal bars indicating the average percent identity within $50-100 \%$

chloroplast genome is lower than that of other species $[6,22,23]$.

We identified 114 indels in the Atractylodes chloroplast genome, including 30 SSR-related and 84 non-SSRrelated. Indels are another important class of genetic variation in addition to nucleotide substitutions. In SSRrelated indels, polymerase slippage results in addition or deletion of short spans of sequences that repeat at one side of the region flanking the indels [24]. The majority of the SSR-related indels are primarily detected in the
AT-regions [25]. Intramolecular recombination and hairpins or the stem-loop secondary structure are causing the majority of the non-SSR-related mutations [26]. In most cases, the non-SSR-related indels are more frequent than SSR-related indels [26]. In Atractylodes, the non-SSR-related indels are more than two-fold frequent than the SSR-related indels. Nucleotide divergence is significantly correlated with size and abundance of the nearby indels [27-29], which indicate that indels are associated mutation hotspots.

Table $\mathbf{3}$ Variable site analyses of Atractylodes chloroplast genomes

\begin{tabular}{|c|c|c|c|c|c|c|}
\hline \multirow[t]{2}{*}{ Regions } & \multirow[t]{2}{*}{ Length } & \multicolumn{2}{|c|}{ Variable sites } & \multicolumn{2}{|c|}{ information sites } & \multirow{2}{*}{$\begin{array}{l}\text { Nucleotide } \\
\text { diversity }\end{array}$} \\
\hline & & Numbers & $\%$ & Numbers & $\%$ & \\
\hline LSC & 84,501 & 310 & 0.3669 & 22 & 0.0260 & 0.0013 \\
\hline IR & 25,153 & 19 & 0.0755 & 1 & 0.0040 & 0.0003 \\
\hline SSC & 18,753 & 97 & 0.5173 & 7 & 0.0373 & 0.0018 \\
\hline Complete chloroplast genome & 153,560 & 445 & 0.2898 & 31 & 0.0202 & 0.0010 \\
\hline
\end{tabular}




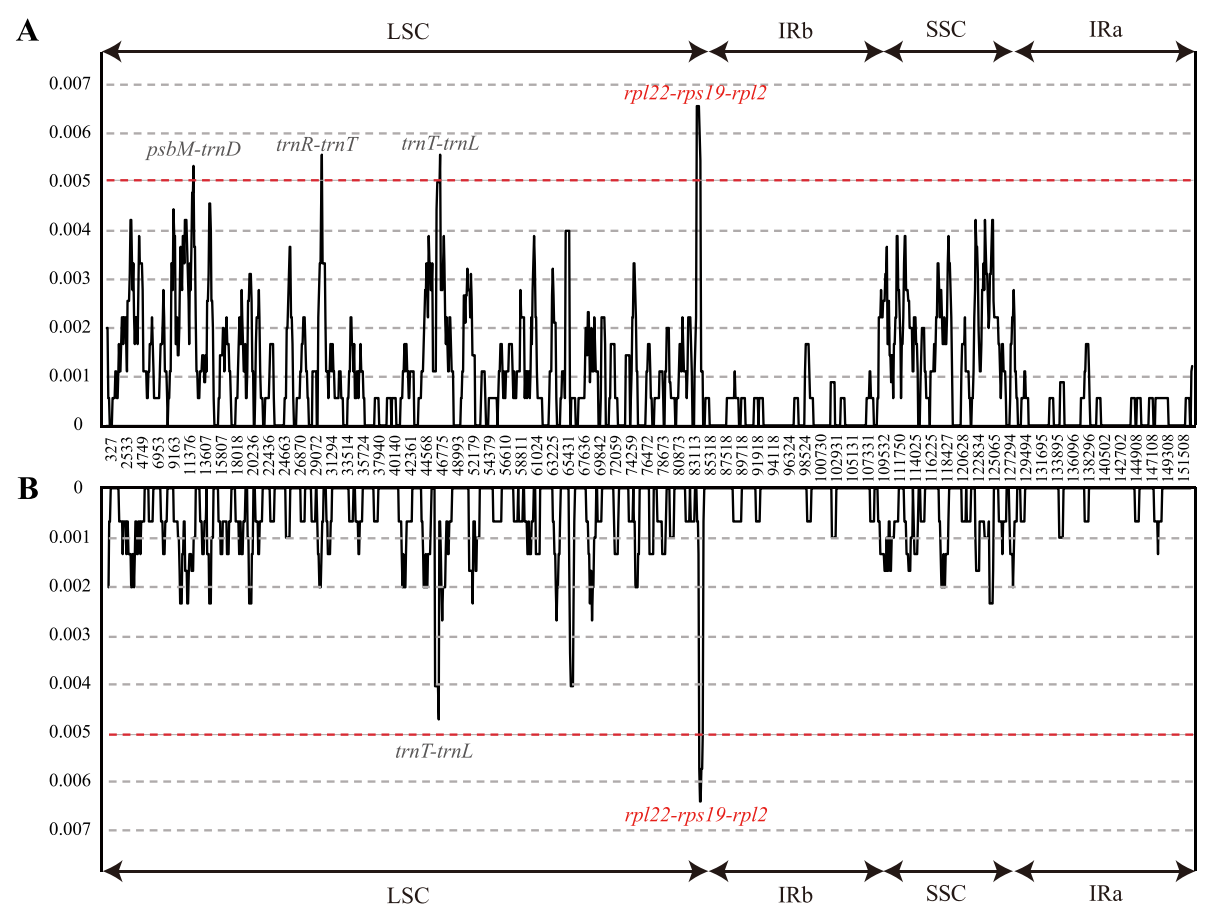

Fig. 6 Sliding-window analysis of the whole chloroplast genomes. (A) All six Atractylodes species (B) Five species used in herbal medicine excluding A. carlinoides. Window length: 600 bp; step size: $100 \mathrm{bp}$. X-axis: position of the midpoint of a window. Y-axis: nucleotide diversity of each window

\section{Phylogenetic relationships}

Atractylodes is a small genus with six species. However, due to low genetic divergence and similar morphology, the systematic relationship of Atractylodes remains unclear. Use of several chloroplast markers, such as (atpB$r b c L, p s b B-F, \operatorname{trn} L-F)$, for phylogenetic resolution is insufficient to draw the firm conclusions about the interspecies relationships in Atractylodes [15-17]. Therefore, sampling of additional more genetic features is expected to improve phylogenetic resolution. Large-scale application of high-throughput technology enhanced availability of the sequencing of the whole chloroplast genomes resulting in resolution of closely related species using plastome sequences [5, 30, 31].

In this study, we used the plastome sequences to assess the phylogenetic relationships within Atractylodes. The results indicate the presence of the deep phylogenetic relationships in Atractylodes. A. carlinoides is located at the base of the genus and $A$. macrocephala was separated later [16]. The taxonomic controversy of Atractylodes is predominantly concentrated in the $A$. lancea complex, which includes four species $A$. coreana, A. chinensis, A. japonica and A. lancea. A. japonica is distributed in Northeast China, Korean, and Japan, and it has a synonym of Atractylodes lancea in "Flora of China". According to the chloroplast genome data, A. japonica and $A$. lancea are clustered into a clade. The morphology of $A$. japonica differs from the other species of the A. lancea complex; for example, the leaves of $A$. japonica have long petioles and are generally divided or completely divided into 3-5 lobes [16]. A. chinensis is considered a species or a variant of $A$. lancea var. chinensis or a synonym of $A$. lancea; this classification has been an issue of controversy. Based on the morphology, A. chinensis is difficult to distinguish from $A$. lancea. Phylogeny of Atractylodes indicates that A. chinensis is a sister of $A$. coreana (Fig. 7). A. lancea is a polytype species based on the morphology [32, 33] and ITS and $\operatorname{trn} L-F$ of multiple individuals [16]. A. coreana is distributed only in the Liaodong and Shadong Peninsulas. Peng et al. treated this species as a synonym of $A$. chinensis based on the trnL-F and ITS data. In this study, the chloroplast genome data provide effective markers to infer the phylogeny of Atractylodes. However, sampling of additional individuals of the species of the $A$. lancea complex can provide additional evidence of evolutionary history.

\section{Potential highly variable chloroplast barcodes}

Increasing number of case studies indicate that the universal DNA barcodes have lower divergence and poor discriminatory power [12]. In Atractylodes, these regions lack variability and may lead to unsuccessful identification and confusing relationships between the species (Table 4). Atractylodes is an important commodity of Chinese medicinal plants; the lack of genomic resources 


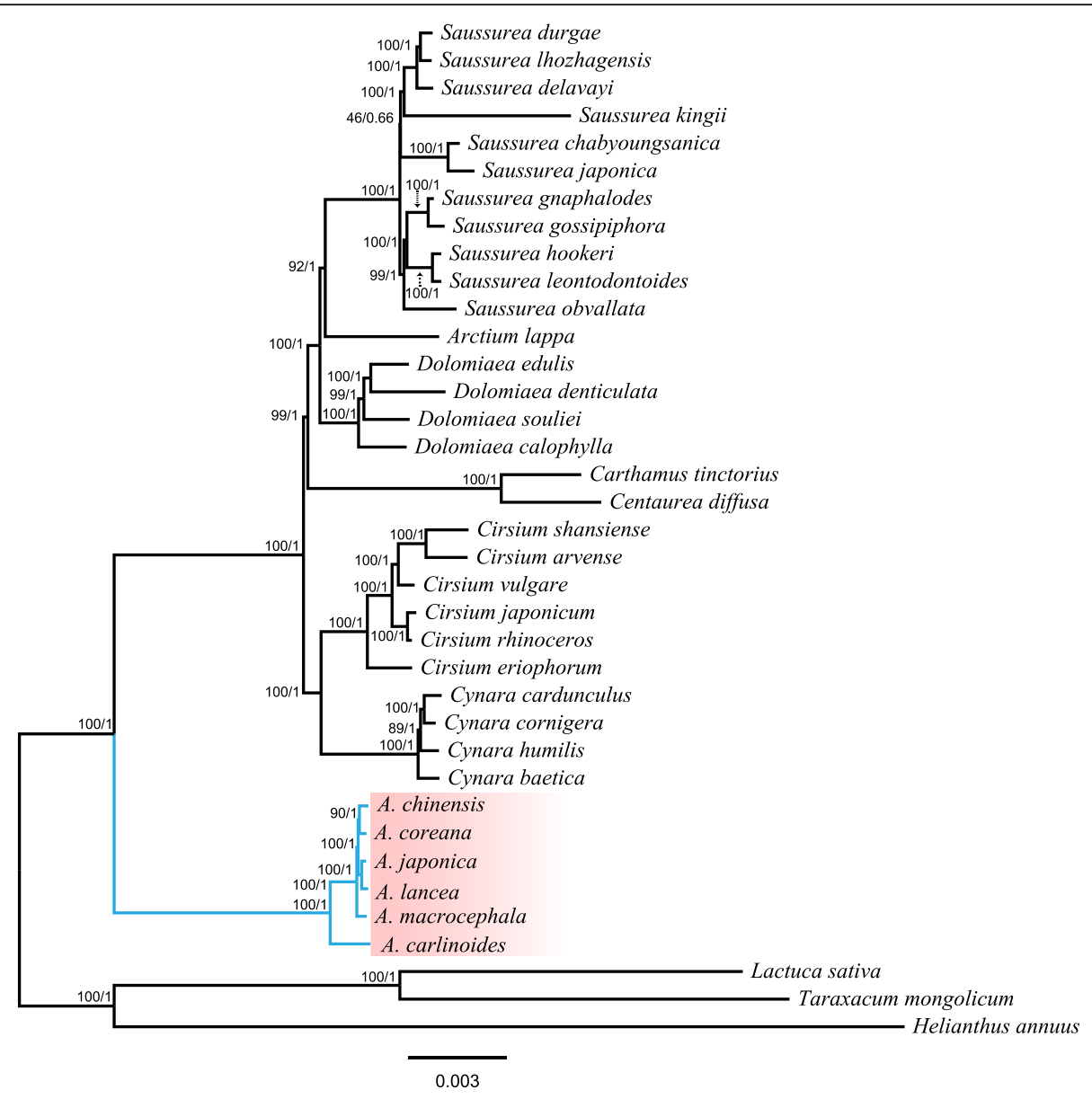

Fig. 7 Phylogenetic tree constructed using the maximum likelihood (ML) and Bayesian inference (BI) methods based on the whole chloroplast genomes from 37 different species. The numbers above the branches represent the ML bootstrap values/BI posterior probabilities

for Atractylodes is the main obstacle to taxonomy, genetics, identification and conservation. Chloroplast genome sequences provide an opportunity to illustrate the genome evolution and generate valuable genetic resources for further studies. The mutation events in the chloroplast genome are not universally randomly distributed within the sequence and are concentrated in certain regions forming the "hotspot" regions [12]. Comparison of the chloroplast genome sequences is an effective strategy to identify the mutation hotspots and these highly variable regions can be used as the specific DNA barcodes. In this study, we identified four hypervariable regions, including rpl22-rps19-rpl2, psbM-trnD, trnR$\operatorname{trn} T^{(\mathrm{GGU})}$, and $\operatorname{trn} T^{(U G U)}-\operatorname{trnL}$.

The $p s b M-t r n D$ region is a part of the trnC-trnD intergenic marker which is divided into three intergenic regions, trnC-pet $N$, pet $N-p s b M$, and $p s b M-t r n D$. The $p s b M-t r n D$ region has a long history of use in the plant phylogenetic studies [34]. The $\operatorname{trn} T^{(U G U)}$-trnL was a part of rps4-trnT ${ }^{(U G U}$ and was suggested by [35] as a high level variability marker; the region is used in certain groups for molecular studies of low taxonomic markers [36]. The rpl22-rps19-rpl2 region consists of two intergenic spaces (rpl22-rps19 and rps19-rpl2) and a coding gene (rps19) with an average size of $1104 \mathrm{bp}$; this region is the most variable marker in the Atractylodes chloroplast genome (Fig. 6 and Table 4). However, this marker was not extensively used in plant phylogeny and DNA barcoding. The trnR-trnT ${ }^{(G G U)}$ was identified for the first time in this study and can be used in the subsequent studies.

\section{Conclusions}

In this study, we sequenced and assembled the complete chloroplast genomes of six Atractylodes species, providing valuable genomic resource of this genus. Based on whole chloroplast phylogenomic analysis, the relationship within the genus was clearly resolved for the first time. Meanwhile, the comparative analysis of chloroplast genomes generated variable regions which could be used as the specific DNA barcodes. All the obtained genetic resources 
will facilitate future studies in population genetics, species identification and conservation biology of Atractylodes.

\section{Methods}

\section{Plant materials and DNA extraction}

The materials of Atractylodes species were obtained from the herbarium of PE (Herbarium, Institute of Botany, CAS) and CMMI (Institute of Chinese Materia Medica, China Academy of Chinese Medical Sciences). Total DNA was extracted following the method of $\mathrm{Li}$ et al. [37] and purified by a Wizard DNA cleanup system (Promega, Madison, WI, USA). DNA quality was assessed by spectrophotometry and the integrity was evaluated using a $1 \%(\mathrm{w} / \mathrm{v})$ agarose gel.

\section{Sequencing, assembly, and annotation}

Total DNA was fragmented to $350 \mathrm{bp}$ fragments by ultrasound. A paired-end library was constructed by a NEBNext UltraTM DNA library prep kit, and PE150 sequencing was performed on the Illumina HiSeq X Ten platform.

NGS QC toolkit was used for quality control and to filter the low quality reads. Contigs were assembled from the high quality paired-end reads by using the SPAdes 3.6.1 program [38] $(\mathrm{Kmer}=95)$. Then, the chloroplast genome contigs were selected by the Blast program using the chloroplast genome of $A$. chinensis (NC037484) as a reference [39]. Subsequently, the selected contigs were assembled using Sequencher 4.10. Geneious 8.1 [40] was used to map all reads to the assembled chloroplast genome sequence to verify the assembling accuracy. The complete chloroplast genome sequences were annotated with Plann [41] using A. chinensis (NC037484) as a reference, and a ring diagram was created by using OrganellarGenomeDRAW [42].

\section{Analysis of microstructural mutation events}

Six chloroplast genomes were aligned using MAFFT V7 software [43], and manually adjusted using Se-al 2.0 [44]. The variable mutation sites and parsimony information sites in the chloroplast genome were assigned using MEGA 7.0 [45].

Simple sequence repeats (SSR) were predicted using the Genome-wide Microsatellite Analyzing Tool Package (GMATA) software [46] with the search parameters set at $>10$ repeat units for mononucleotide, $>5$ repeat units for dinucleotide, $>4$ repeat units for trinucleotide, and $>3$ repeat units for tetranucleotide, pentanucleotide, and hexanucleotide SSRs.

Based on the aligned sequence matrix, the indels were manually validated and divided into two categories, including SSR-related and non-SSR-related (normal indels). A. chinensis was used as a reference to determine the size and position of the indels events.

\section{Comparison of the chloroplast genomes and divergent hotspot identification}

Comparison of the whole chloroplast genomes of Atractylodes was performed by the mVISTA program (http:// genome.lbl.gov/vista/mvista/submit.shtml) with the Shuffle-LAGAN mode. Sequence of $A$. chinensis was used as a reference. The nucleotide diversity of the chloroplast genome was calculated based on the sliding window analysis using the DnaSP v5.10 software [47]. The window length was set to $600 \mathrm{bp}$ with a $100 \mathrm{bp}$ step size. A. carlinoides has a well distinguished morphology and five other species were used as a traditional Chinese medicine. Two data sets were created for this analysis: (1) all six species data set (group A) and (2) five medical species (group B).

\section{Phylogenetic reconstruction}

Thirty-seven chloroplast genome sequences were used for phylogenetic analysis, including six Atractylodes samples and 31 samples of other species of Cynareae and Lactuceae from the GenBank (Table S2). All chloroplast genome sequences were aligned using MAFFT and ambiguous alignment regions were trimmed by Gblocks 0.91b [48].

Phylogenetic analysis was carried out using the maximum likelihood (ML) and Bayesian inference (BI)

Table 4 The variability of the hypervariable markers and universal chloroplast DNA barcodes

\begin{tabular}{|c|c|c|c|c|c|c|}
\hline \multirow[t]{2}{*}{ Markers } & \multirow[t]{2}{*}{ Length } & \multicolumn{2}{|c|}{ Variable sites } & \multicolumn{2}{|c|}{ information sites } & \multirow{2}{*}{$\begin{array}{l}\text { Nucleotide } \\
\text { Diversity }\end{array}$} \\
\hline & & Numbers & $\%$ & Numbers & $\%$ & \\
\hline$r b c L$ & 1434 & 3 & 0.21 & 0 & 0.00 & 0.0007 \\
\hline matk & 1520 & 9 & 0.59 & 1 & 0.07 & 0.0021 \\
\hline $\operatorname{trnH}-p s b A$ & 393 & 3 & 0.76 & 1 & 0.25 & 0.0031 \\
\hline$r b c L+$ matK + trnH-psbA & 3347 & 15 & 0.45 & 2 & 0.06 & 0.0016 \\
\hline psbM-trnD & 827 & 10 & 1.21 & 1 & 0.12 & 0.0053 \\
\hline $\operatorname{trn} R-\operatorname{trn} T$ & 715 & 10 & 1.40 & 0 & 0.00 & 0.0056 \\
\hline $\operatorname{trn} T-\operatorname{trn} L$ & 921 & 10 & 1.09 & 0 & 0.00 & 0.0050 \\
\hline rpl22-rps19-rp/2 & 1105 & 13 & 1.18 & 3 & 0.27 & 0.0066 \\
\hline$p s b M-t r n D+\operatorname{trn} R-\operatorname{trn} T+\operatorname{trn} T-\operatorname{trn} L+r p / 22-r p s 19-r p / 2$ & 3568 & 43 & 1.21 & 4 & 0.11 & 0.0042 \\
\hline
\end{tabular}


methods. The optimal model TVM+F+I + G4 was calculated by Modelfinder based on the BIC standard (recommended by the software) [49]. ML calculations were performed using the IQ-tree [50], and the sampling was repeated 1000 times. Bayesian inference (BI) of the phylogenies was implemented with MrBayes [51]. The Markov chain Monte Carlo (MCMC) analysis was run for $10,000,000$ generations. The trees were sampled every 1000 generations and the initial $25 \%$ were discarded as burn-in. Finally, average standard deviation of the split frequencies $<0.01$ was verified. And the phylogenetic analysis by using obtained indel data (including SSRs) was conducted by MEGA 7.0 in ML method.

\section{Supplementary Information}

The online version contains supplementary material available at https:/doi. org/10.1186/s12864-021-07394-8

Additional file 1 Fig. S1. Phylogenetic tree constructed using the maximum likelihood (ML) methods based on the obtained indel data of Atractylodes species.

Additional file 2. Table S1. Detailed information of indels.

Additional file 3. Table S2. Information on the chloroplast genome downloaded from Genbank for phylogenetic analysis.

\section{Abbreviations}

BI: Bayesian inference; IR: inverted repeat region; LSC: large single copy region; ML: Maximum Likelihood; rRNA: Ribosomal RNA; SSR: simple sequence repeats; SSC: small single copy region; tRNA: Transfer RNA

\section{Acknowledgements}

The authors would like to thank Teng Zhang and Chao Xu for providing plant materials.

\section{Authors' contributions}

YW and SW did the data analysis and wrote the manuscript; YL and YW participated in the experiments; QY and JS participated in collection of study materials; JS and LG conceived and designed the research. The authors read and approved the final manuscript.

\section{Funding}

This work was financially supported by National Natural Science Foundation of China (No.81891014 \& No.81874337). The funding agencies had no role in the design of the experiment, analysis, and interpretation of data and in writing the manuscript.

\section{Availability of data and materials}

Six annotated chloroplast sequences have been submitted to NCBI (https:// www.ncbi.nlm.nih.gov) with accession numbers: MT834519 MT834524. The reference sequence for assembly and annotation was obtained from NCBI with accession number: NC037484, (https://www.ncbi.nlm.nih.gov/nuccore/ NC_037484), Information for phylogenetic analysis download from Genbank can be found in Table S2. All raw reads are available in the short sequence archive under accession no. PRJNA692669.

\section{Ethics approval and consent to participate}

Not applicable.

\section{Consent for publication}

Not applicable.

\section{Competing interests}

The authors declare that they have no conflict of interest.

\section{Author details}

'National Resource Center for Chinese Materia Medica, China Academy of Chinese Medical Sciences, Beijing 100700, China. ${ }^{2}$ State Key Laboratory of Systematic and Evolutionary Botany, Institute of Botany, Chinese Academy of Sciences, Beijing 100093, China.

Received: 12 August 2020 Accepted: 19 January 2021

Published online: 04 February 2021

\section{References}

1. Cheng H, Li JF, Zhang H, Cai BH, Gao ZH, Qiao YS, Mi L. The complete chloroplast genome sequence of strawberry (Fragaria $\mathrm{X}$ ananassa Duch.) and comparison with related species of Rosaceae. Peerj. 2017:5.

2. Dong W, Xu C, Cheng T, Lin K, Zhou S. Sequencing angiosperm plastid genomes made easy: a complete set of universal primers and a case study on the phylogeny of Saxifragales. Genome Biol Evol. 2013;5(5):989-97.

3. Dong WP, Liu J, Yu J, Wang L, Zhou SL. Highly Variable Chloroplast Markers for Evaluating Plant Phylogeny at Low Taxonomic Levels and for DNA Barcoding. PLoS One. 2012:7(4)

4. Twyford AD, Ness RW. Strategies for complete plastid genome sequencing. Mol Ecol Resour. 2017;17(5):858-68.

5. Dong W, Xu C, Wu P, Cheng T, Yu J, Zhou S, Hong D-Y. Resolving the systematic positions of enigmatic taxa: manipulating the chloroplast genome data of Saxifragales. Mol Phylogenet Evol. 2018;126:321-30.

6. Li W, Liu Y, Yang Y, Xie X, Lu Y, Yang Z, Jin X, Dong W, Suo Z. Interspecific chloroplast genome sequence diversity and genomic resources in Diospyros. BMC Plant Biol. 2018;18(1):210.

7. Dong W, Xu C, Li W, Xie X, Lu Y, Liu Y, Jin X, Suo Z. Phylogenetic resolution in Juglans based on complete chloroplast genomes and nuclear DNA sequences. Front Plant Sci. 2017;8:1148

8. Liu HS, Su ZH, Yu SQ, Liu JL, Yin XJ, Zhang GW, Liu W, Li B. Genome comparison reveals mutation hotspots in the chloroplast genome and phylogenetic relationships of Ormosia species. Biomed Res Int. 2019;2019.

9. Meng J, Li XP, Li HT, Yang JB, Wang H, He J. Comparative Analysis of the Complete Chloroplast Genomes of Four Aconitum Medicinal Species. Molecules. 2018:23(5).

10. Mader M, Pakull B, Blanc-Jolivet C, Paulini-Drewes M, Bouda ZHN, Degen B, Small I, Kersten B. Complete Chloroplast Genome Sequences of Four Meliaceae Species and Comparative Analyses. Int J Mol Sci. 2018:19(3).

11. Yang Z, Zhao T, Ma QH, Liang LS, Wang GX. Comparative genomics and phylogenetic analysis revealed the chloroplast genome variation and interspecific relationships of Corylus (Betulaceae) species. Front Plant Sci. 2018;9.

12. Dong W, Liu J, Yu J, Wang L, Zhou S. Highly variable chloroplast markers for evaluating plant phylogeny at low taxonomic levels and for DNA barcoding. PLoS One. 2012;7(4):e35071.

13. Peng HS, Wang DQ. The history and differentiation of raw Atractylodes commodity in successive ages. Zhonghua Yi Shi Za Zhi. 2007;37(1):15-8

14. Kohjyouma M, Nakajima S, Namera A, Shimizu R, Mizukami H, Kohda H. Random amplified polymorphic DNA analysis and variation of essential oil components of Atractylodes plants. Biol Pharm Bull. 1997;20(5):502-6.

15. Ge YF, Hang YY, Xia B, Wei YL. Sequencing of trnL-F and analysis of interspecific genetic relationship of five medicinal species in Atractylodes DC. J Plant Resour Environ. 2007:16:12-6.

16. Peng HS, Yuan Q, Li Q, Huang L. Molecular systematics of genus Atractylodes (Compositae, Cardueae): evidence from internal transcribed spacer (ITS) and trnL-F sequences. Int J Mol Sci. 2012;13(11):14623-33.

17. Zou XX, Huang LQ, Cui GH, Yuan QJ, Peng Y, Liu Y, Xiao PG. Genetic relationships of Atractylodes plants. Acta Pharm Sin. 2009;44(6):680-6.

18. Lu RS, Li P, Qiu YX. The complete chloroplast genomes of three Cardiocrinum (Liliaceae) species: comparative genomic and phylogenetic analyses. Front Plant Sci. 2016;7:2054.

19. Wicke S, Schneeweiss GM, De Pamphilis CW, Muller KF, Quandt D. The evolution of the plastid chromosome in land plants: gene content, gene order, gene function. Plant Mol Biol. 2011;76(3-5):273-97.

20. Oliver MJ, Murdock AG, Mishler BD, Kuehl JV, Boore JL, Mandoli DF, Everett KD, Wolf PG, Duffy AM, Karol KG. Chloroplast genome sequence of the moss Tortula ruralis: gene content, polymorphism, and structural arrangement relative to other green plant chloroplast genomes. BMC Genomics. 2010;11:143. 
21. Jansen RK, Cai Z, Raubeson LA, Daniell H, Depamphilis CW, Leebens-Mack J, Muller KF, Guisinger-Bellian M, Haberle RC, Hansen AK, et al. Analysis of 81 genes from 64 plastid genomes resolves relationships in angiosperms and identifies genome-scale evolutionary patterns. Proc Natl Acad Sci U S A. 2007;104(49):19369-74.

22. Xu C, Dong W, Li W, Lu Y, Xie X, Jin X, Shi J, He K, Suo Z. Comparative analysis of six Lagerstroemia complete chloroplast genomes. Front Plant Sci. 2017:8(15):15.

23. Song Y, Chen Y, Lv J, Xu J, Zhu S, Li M, Chen N. Development of chloroplast genomic resources for Oryza species discrimination. Front Plant Sci. 2017;8: 1854.

24. Graham SW, Reeves PA, Burns ACE, Olmstead RG. Microstructural changes in noncoding chloroplast DNA: interpretation, evolution, and utility of indels and inversions in basal angiosperm phylogenetic inference. Int J Plant Sci. 2000;161(6):S83-96.

25. Gandhi SG, Awasthi P, Bedi YS. Analysis of SSR dynamics in chloroplast genomes of Brassicaceae family. Bioinformation. 2010;5(1):16-20.

26. Song Y, Chen Y, Lv J, Xu J, Zhu S, Li M. Comparative chloroplast genomes of Sorghum species: sequence divergence and phylogenetic relationships. Biomed Res Int. 2019;2019:11.

27. Ahmed I, Biggs PJ, Matthews PJ, Collins LJ, Hendy MD, Lockhart PJ. Mutational dynamics of aroid chloroplast genomes. Genome Biol Evol. 2012; 4(12):1316-23.

28. Tian DC, Wang Q, Zhang PF, Araki H, Yang SH, Kreitman M, Nagylaki T, Hudson R, Bergelson J, Chen JQ. Single-nucleotide mutation rate increases close to insertions/deletions in eukaryotes. Nature. 2008;455(7209):105U170.

29. Hollister JD, Ross-lbarra J, Gaut BS. Indel-associated mutation rate varies with mating system in flowering plants. Mol Biol Evol. 2010;27(2):409-16.

30. Viljoen E, Odeny DA, Coetzee MPA, Berger DK, Rees DJG: Application of Chloroplast Phylogenomics to Resolve Species Relationships Within the Plant Genus Amaranthus. J Mol Evol 2018.

31. Cai C-N, Ma H, Ci X-Q, Conran JG, Li J: Comparative phylogenetic analyses of Chinese Horsfieldia (Myristicaceae) using complete chloroplast genome sequences. J Syst Evol 2019, n/a(n/a).

32. Shi Z. On the nomenclature of Chinese drug "Cangzhu". Acta Phytotaxon Sin. 1981;19(3):318-22.

33. $X u$ GF, Yu YL, Liu J, Wang LX. Observations on the morphological charcter of Atractylodes japonica Koidz. Et Kitam J Jiamusi Med Coll. 1993;16:15-7.

34. Lee C, Wen J. Phylogeny of Panax using chloroplast trnC-trnD intergenic region and the utility of $\operatorname{trnC}-\operatorname{trnD}$ in interspecific studies of plants. $\mathrm{Mol}$ Phylogenet Evol. 2004;31(3):894-903.

35. Shaw J, Lickey EB, Beck JT, Farmer SB, Liu WS, Miller J, Siripun KC, Winder $\mathrm{CT}$, Schilling EE, Small RL. The tortoise and the hare II: relative utility of 21 noncoding chloroplast DNA sequences for phylogenetic analysis. Am J Bot. 2005;92(1):142-66

36. Gao G, Tang Z, Wang Q, Gou X, Ding C, Zhang L, Zhou Y, Yang R. Phylogeny and maternal donor of Kengyilia (Triticeae: Poaceae) based on chloroplast trnT-trnL sequences. Biochem Syst Ecol. 2014;57:102-7.

37. Li JL, Wang S, Yu J, Wang L, Zhou SL. A modified CTAB protocol for plant DNA extraction. Chinese Bulletin of Botany. 2013;48(1):72-8

38. Bankevich A, Nurk S, Antipov D, Gurevich AA, Dvorkin M, Kulikov AS, Lesin VM, Nikolenko SI, Pham S, Prjibelski AD, et al. SPAdes: a new genome assembly algorithm and its applications to single-cell sequencing. J Comput Biol. 2012;19(5):455-77.

39. Altschul SF, Gish W, Miller W, Myers EW, Lipman DJ. Basic local alignment search tool. J Mol Biol. 1990;215(3):403-10

40. Kearse M, Moir R, Wilson A, Stones-Havas S, Cheung M, Sturrock S, Buxton S, Cooper A, Markowitz S, Duran C, et al. Geneious basic: an integrated and extendable desktop software platform for the organization and analysis of sequence data. Bioinformatics. 2012;28(12):1647-9.

41. Huang DI, Cronk QCB. Plann: a command-line application for annotating plastome sequences. Applications in Plant Sciences. 2015;3(8):1500026.

42. Lohse M, Drechsel O, Bock R. OrganellarGenomeDRAW (OGDRAW): a tool for the easy generation of high-quality custom graphical maps of plastid and mitochondrial genomes. Curr Genet. 2007:52(5-6):267-74.

43. Katoh K, Standley DM. MAFFT multiple sequence alignment software version 7: improvements in performance and usability. Mol Biol Evol. 2013, 30(4):772-80.

44. Rambaut A: Se-Al: sequence alignment editor. Version 2.0. 1996:http://tree. bio.ed.ac.uk/software/seal/.
45. Kumar S, Nei M, Dudley J, Tamura K. MEGA: a biologist-centric software for evolutionary analysis of DNA and protein sequences. Brief Bioinform. 2008; 9(4):299-306.

46. Wang XW, Wang L. GMATA: an integrated software package for genomescale SSR mining, marker development and Vlewing. Front Plant Sci. 2016;7.

47. Librado P, Rozas J. DnaSP v5: a software for comprehensive analysis of DNA polymorphism data. Bioinformatics. 2009;25(11):1451-2.

48. Castresana J. Selection of conserved blocks from multiple alignments for their use in phylogenetic analysis. Mol Biol Evol. 2000;17(4):540-52.

49. Zhang D, Gao F, Jakovlic I, Zou H, Zhang J, Li WX, Wang GT. PhyloSuite: an integrated and scalable desktop platform for streamlined molecular sequence data management and evolutionary phylogenetics studies. Mol Ecol Resour. 2020;20(1):348-55.

50. Nguyen LT, Schmidt HA, von Haeseler A, Minh BQ. IQ-TREE: a fast and effective stochastic algorithm for estimating maximum-likelihood phylogenies. Mol Biol Evol. 2015;32(1):268-74.

51. Ronquist $F$, Teslenko M, van der Mark $P$, Ayres DL, Darling A, Hohna S, Larget B, Liu L, Suchard MA, Huelsenbeck JP. MrBayes 3.2: efficient Bayesian phylogenetic inference and model choice across a large model space. Syst Biol. 2012;61(3):539-42.

\section{Publisher's Note}

Springer Nature remains neutral with regard to jurisdictional claims in published maps and institutional affiliations.
Ready to submit your research? Choose BMC and benefit from:

- fast, convenient online submission

- thorough peer review by experienced researchers in your field

- rapid publication on acceptance

- support for research data, including large and complex data types

- gold Open Access which fosters wider collaboration and increased citations

- maximum visibility for your research: over $100 \mathrm{M}$ website views per year

At $\mathrm{BMC}$, research is always in progress.

Learn more biomedcentral.com/submissions 